\title{
Precision Information Environment (PIE) for International Safeguards: Pre-Demonstration Development Use Cases
}

\author{
ZN Gastelum \\ MJ Henry
}

November 2013

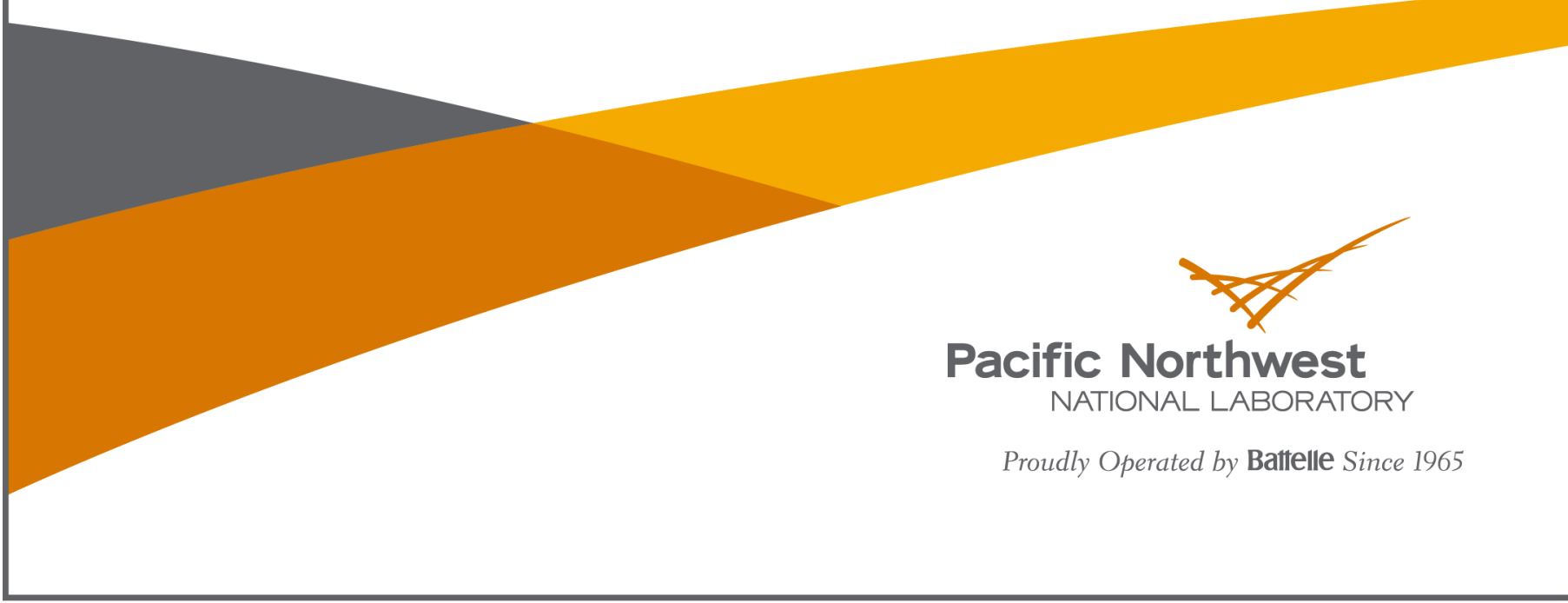




\title{
DISCLAIMER
}

This report was prepared as an account of work sponsored by an agency of the United States Government. Neither the United States Govemment nor any agency thereof, nor Battelle Memorial Institute, nor any of their employees, makes any warranty, express or implied, or assumes any legal liability or responsibility for the accuracy, completeness, or usefulness of any information, apparatus, product, or process disclosed, or represents that its use would not infringe privately owned rights. Reference herein to any specific commercial product, process, or service by trade name, trademark, manufacturer, or otherwise does not necessarily constitute or imply its endorsement, recommendation, or favoring by the United States Government or any agency thereof, or Battelle Memorial Institute. The views and opinions of authors expressed herein do not necessarily state or reflect those of the United States Government or any agency thereof.

\author{
PACIFIC NORTHWEST NATIONAL LABORATORY \\ operated by \\ BATTELLE \\ for the \\ UNITED STATES DEPARTMENT OF ENERGY \\ under Contract DE-AC05-76RL01830
}

Printed in the United States of America

Available to DOE and DOE coetractors from the Office of Scientific and Technical Information, P.O. Bos 62, Oak Ridge, TN 37831-0062:

ph: (865) 576-8.401 fax: $(865) 576-5728$

cmail: reports $\alpha$ adonis,osti-gov

Available to the pablic from the National Technical Information Service 5301 Shawnee Rd., Alexandria, VA 22312

ph: (800) \$53-NTIS (6847)

email: ordersantis. gov <http://www.ntis.gov/about/form.asps?

Online ordering: http:/www,ntis,gov 


\section{Precision Information Environment (PIE) for International Safeguards: Pre-Demonstration Development Use Cases}

ZN Gastelum

MJ Henry

November 2013

Prepared for

the U.S. Department of Energy

under Contract DE-AC05-76RL01830

Pacific Northwest National Laboratory

Richland, Washington 99352 



\section{Contents}

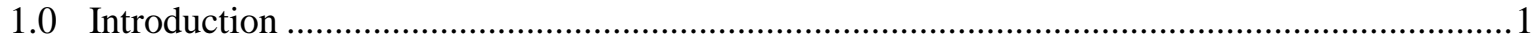

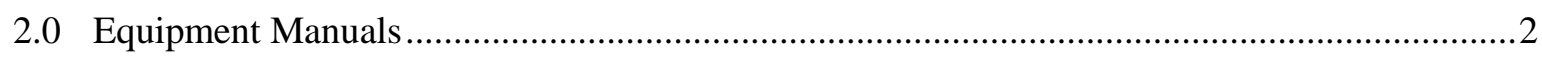

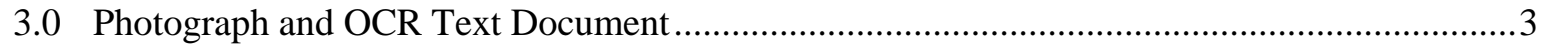

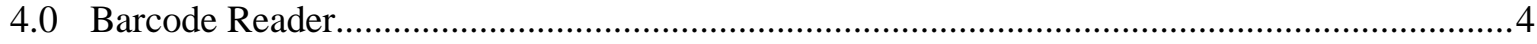

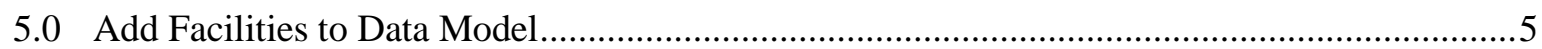

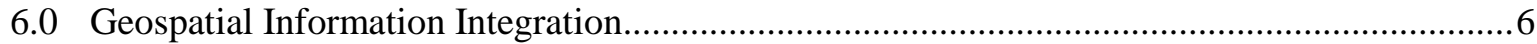



PNNL-22963

\subsection{Introduction}

In FY2013, the PIE International Safeguards team demonstrated our development progress to U.S. Department of Energy (DOE) staff from the Office of Nonproliferation and International Security (NA24, our client) and the Office of Defense Nuclear Nonproliferation Research and Development (NA-22). Following the demonstration, the team was asked by our client to complete additional development prior to a planned demonstration at the International Atomic Energy Agency (IAEA), scheduled tentatively for January or spring of 2014. The team discussed four potential areas for development (in priority order), and will develop them as time and funding permit prior to an IAEA demonstration. The five capability areas are:

1. Addition of equipment manuals to PIE-accessible files

2. Optical character recognition (OCR) of photographed text

3. Barcode reader with information look-up from a database

4. Add Facilities to Data Model

5. Geospatial capabilities with information integration

Each area will be described below in a use case.

The purpose of this document is to describe the capabilities that will be developed for PIE International Safeguards in FY2014. The document is intended for use by project management to track and test project status, and for developers as initial technical requirements. 


\subsection{Equipment Manuals}

A set of documents will be compiled on the PIE-IAEA share drive labeled "Equipment Manuals." The documents should be associated with an activity, and viewable in the tasks. The documents should in a separate tab from other files, labeled "Manuals."

Upon opening an existing activity, selecting a task, and selecting the Manuals tab, the user will be able to scroll through, open, and close the manuals in the same manner as they would files associated with each task. Equipment manual files may be in the form of .doc or .pdf. All equipment manuals should be attached to the activity/task, no matter which task(s) is selected.

Note for Future Work: While we do not need to have equipment manuals auto-select based on assigned tasks this FY, we should leave this open as an option for future development. 


\subsection{Photograph and OCR Text Document}

Using the camera on the tablet, accessed via PIE-Safeguards, the user will take a photograph of a document with typed text. The text may be prose or interspersed with photographs. Upon saving the photo, PIE will run optical character recognition (OCR) software over the text of the document, at which point PIE will give the user two options: save the photo, or save the OCR file (with previews of each). All OCR processing will be done on the tablet. Depending on which is selected, that file will be saved with other files associated with the task

The PIE team will also conduct preliminary explorations for eliminating noise (formatting/images) within the text, and the performance of the system will be characterized. 
PNNL-22963

\subsection{Barcode Reader}

A database will be developed with several example barcodes representing radiation detection equipment, and associated technical specification data. The information for the database will be collected and stored on the PIE-Safeguards share drive in a folder named "Barcode Data."

Using a barcode reader accessible from within a PIE task (there should be a button for barcode scanning), the user will scan a barcode (either on a piece of equipment, or on apper). All barcode processing will be done on the tablet. PIE-Safeguards will look the barcode up from the specified database, and will return the database's information regarding the scanned barcode in an easy-to-read format. The information returned from the database may include photographs, technical specifications, and other information specified in the database regarding that piece of equipment. The data in PIE should be read-only.

Upon scanning the barcode, PIE will also direct the user to the user manual for that piece of equipment stored in the "Equipment Manuals" folder on the server which we are using for the Equipment Manuals use case in Section 2.0. 
PNNL-22963

\subsection{Add Facilities to Data Model}

In order to support the Geo View (See Section6.0), modifications to the data model are necessary. An Activity remains at the top of the data hierarchy. Each Activity will contain one or more Tasks, identical to how things were done in FY13 (user selectable on create), and exactly one Country. Within the data model, Countries will contain one or more Facilities. No two facilities should have the same name either within a Country or elsewhere. A Facility will contain one or more Files. Files, in this sense, are the same as the Files associated with a task. Files will continue to be associated with DIV, PIV, and IIV the same as in FY13. Files may also be associated with Geo (not mutually exclusive). Files associated with Geo will be shown in the Geo View as described in Section 6.0.

Facilities will be present through the UI within two components: Creating a new Activity, and the Geo View.

\section{Creating A New Activity}

While creating a new Activity, users will be prompted to select a Country, same as what was done in FY13. A new view will be created that will prompt the user to select one or more facilities from a list, filtered based on the previously selected Country. Tasks will be selected the same as before. Each Facility within the Country has a unique set of files associated with it. All Files are associated with a Task (ie. no Files are just associated with the Geo View).

Files are implicitly tagged (or otherwise associated) with one or more of the following:
1. DIV
2. PIV
3. IIV
4. Geo (NEW)

The PIE-IAEA will download from the server all the Files associated with the Tasks they selected (same as before) as well as any Files associated with Geo. As an example, if the user picks PIV as the only Task, but none of the Files associated with PIV are also associated with Geo (as an example). The Files associated with Geo will always be downloaded to the PIE-Safeguards client with the creation of a new Activity, even if they are also associated with a Task that was not selected. The Geo Files will not be accessible through the Tasks View unless they are also associated with a selected Task; in that case they'll only be viewable through the Geo View.

\section{Geo View}

While in the Tasks view (Open Existing -> Select An Activity -> Select A Task) a link to the Geo View will be available. This will open a new Android Activity with the Geo View, as described in Section 6.0 


\subsection{Geospatial Information Integration}

Upon opening an existing Activity and Task, the user will have the option to view and access related information via a "Geo" view. The user should be able to navigate within the map using standard finger gestures for left/right/up/down scrolling, as well as zoom in/zoom out. When the user selects the "geo" view, he/she will see the location of the selected facility on a map. If the user selects the facility by tapping it, a box with additional information will pop up including the facility name, and a list of available "geo" documents (Microsoft office documents, PDF, images, or video files). Image files should be thumbnails, video files should be thumbnails with a glyph indicating that it's a video, and other documents should be an icon that indicates which type of file it is.

Other facilities in the region should be visible on the map, but in a less-prominent manner than the facility for the selected activity (i.e. greyed out). Those facility names should be available if the facility is selected, but associated files will not be provided.

The development of this capability is dependent on funding and direction from the client. It will include the following:

1. Hook in with Google Maps Android API

2. Add the concept of a "Facility" to the PIE-Safeguards server and data model. See Section 5.0.

3. Add information overlays to the map. When the user selects a facility on the map, PIE-Safeguards will open an information overlap onto the map. The information will include any files/documents that are tagged as "geo" and may include:
a. Satellite imagery reports, from the server
b. Other images associated with the facility
c. Reports related to facility

Based on client funding and direction, full functionality might be reduced. The team will have to be agile and adjust based on possible changes in scope mid-year. For example, \#3 above may be replaced by a display of Facilities on the map without associated information. (A spreadsheet will be provided with a list of nuclear fuel cycle facilities and their latitude and longitude coordinates.) 


\section{Distribution}

No. of

Copies

(1) David Peranteau

NA-24

955 L'Enfant Plaza, N

Washington, D.C., 20024

(1) Hilary Lane

NA-24

955 L'Enfant Plaza, N

Washington, D.C., 20024

(1) Jessica Buford

NA-24

955 L'Enfant Plaza, N

Washington, D.C., 20024
No. of

\section{Copies}

\# Local Distribution

Pacific Northwest National Laboratory

Jason Shergur

J4-60

Kevin Whattam

K8-50

Distr.1 




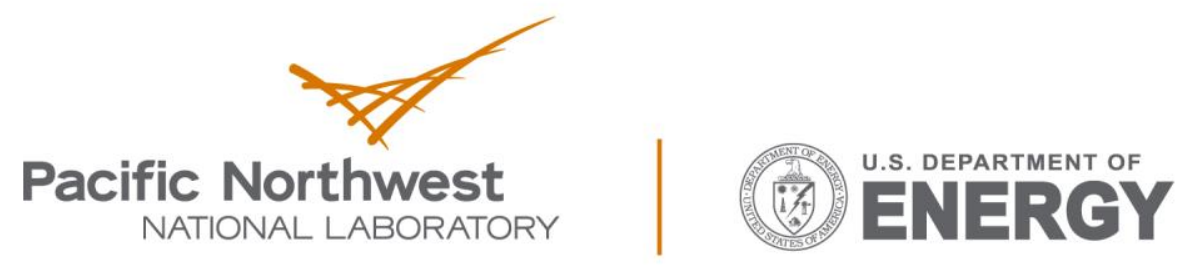

Proudly Operated by Battelle Since 1965

902 Battelle Boulevard

P.O. Box 999

Richland, WA 99352

1-888-375-PNNL (7665)

www.pnnl.gov 